\title{
Synthesis, characterisation and thermoelectric properties of the oxytelluride Bi2O2Te
}

Article

Accepted Version

Luu, S. D.N. and Vaqueiro, P. (2015) Synthesis, characterisation and thermoelectric properties of the oxytelluride Bi2O2Te. Journal of Solid State Chemistry, 226. pp. 219-223. ISSN 0022-4596 doi:

https://doi.org/10.1016/j.jssc.2015.02.026 Available at https://centaur.reading.ac.uk/39759/

It is advisable to refer to the publisher's version if you intend to cite from the work. See Guidance on citing.

To link to this article DOI: http://dx.doi.org/10.1016/j.jssc.2015.02.026

Publisher: Elsevier

All outputs in CentAUR are protected by Intellectual Property Rights law, including copyright law. Copyright and IPR is retained by the creators or other copyright holders. Terms and conditions for use of this material are defined in the End User Agreement.

www.reading.ac.uk/centaur 
Central Archive at the University of Reading

Reading's research outputs online 


\title{
Synthesis, characterisation and thermoelectric properties of the oxytelluride $\mathrm{Bi}_{2} \mathrm{O}_{2} \mathrm{Te}$
}

\author{
Son D. N. Luu ${ }^{1,2}$ and Paz Vaqueiro ${ }^{2 *}$ \\ ${ }^{1}$ Institute of Chemical Sciences, Heriot-Watt University, Edinburgh, EH14, 4AS, UK \\ ${ }^{2}$ Department of Chemistry, University of Reading, Whiteknights, Reading, RG6 6AD, UK
}

Corresponding author:

Dr Paz Vaqueiro

Department of Chemistry

University of Reading

Reading RG6 6AD

E-mail: p.vaqueiro@reading.ac.uk 


\begin{abstract}
$\mathrm{Bi}_{2} \mathrm{O}_{2} \mathrm{Te}$ was synthesised from a stoichiometric mixture of $\mathrm{Bi}, \mathrm{Bi}_{2} \mathrm{O}_{3}$ and $\mathrm{Te}$ by a solid state reaction. Analysis of powder X-ray diffraction data indicates that this material crystallises in the anti- $\mathrm{ThCr}_{2} \mathrm{Si}_{2}$ structure type (space group $14 / \mathrm{mmm}$ ), with lattice parameters $a=$ 3.98025(4) and $c=12.70391(16) \AA$. The electrical and thermal transport properties of $\mathrm{Bi}_{2} \mathrm{O}_{2}$ Te were investigated as a function of temperature over the temperature range $300 \leq \mathrm{T} / \mathrm{K}$ $\leq 665$. These measurements indicate that $\mathrm{Bi}_{2} \mathrm{O}_{2}$ Te is an $n$-type semiconductor, with a band gap of $0.23 \mathrm{eV}$. The thermal conductivity of $\mathrm{Bi}_{2} \mathrm{O}_{2} \mathrm{Te}$ is remarkably low for a crystalline material, with a value of only $0.91 \mathrm{~W} \mathrm{~m}^{-1} \mathrm{~K}^{-1}$ at room temperature.
\end{abstract}




\section{Introduction}

Thermoelectric energy recovery, which enables direct conversion of heat into useful electrical energy, is a promising energy conversion technology [1]. However, wide-scale implementation of thermoelectric power generation requires improvements in the efficiency of energy recovery. In particular, the conversion efficiency is related to the figure of merit of the thermoelectric materials used in thermoelectric devices. This dimensionless figure of merit is given by the expression $\mathrm{ZT}=\mathrm{S}^{2} \sigma \mathrm{T} / \kappa$, where $\mathrm{S}, \sigma$, T and $\kappa$ are the Seebeck coefficient, the electrical conductivity, the absolute temperature and the thermal conductivity, respectively. A good thermoelectric material should exhibit a large electrical conductivity and Seebeck coefficient, combined with a low thermal conductivity [2]. The need for thermoelectric devices with higher efficiencies has led to increased research efforts in the search for new thermoelectric materials. Recent advances in promising bulk thermoelectric materials have been reviewed [3].

While the thermoelectric properties of bismuth chalcogenides have been extensively investigated [4], little is known about bismuth oxychalcogenides. The existence of $\mathrm{Bi}_{2} \mathrm{O}_{2} \mathrm{Se}$, which crystallises in the anti- $\mathrm{ThCr}_{2} \mathrm{Si}_{2}$ structure type, was first reported by Boller [5]. The BiO-Se phase diagram was studied in detail by Oppermann et al $[6,7,8,9,10,11]$, while the thermoelectric properties of $\mathrm{Bi}_{2} \mathrm{O}_{2} \mathrm{Se}$ were first reported by Ruleova et al. [12]. Experimental $[13,14]$ and theoretical studies $[15,16]$ of this material, which is an $n$-type semiconductor with a reported $\mathrm{ZT}=0.007$ at $300 \mathrm{~K}$ [12], have been carried out. Recently, the related oxychalcogenides $[\mathrm{BiO}][\mathrm{CuQ}](\mathrm{Q}=\mathrm{S}, \mathrm{Se}, \mathrm{Te})$, which consist of $\left[\mathrm{Bi}_{2} \mathrm{O}_{2}\right]^{2+}$ layers alternating with $\left[\mathrm{Cu}_{2} \mathrm{Q}_{2}\right]^{2-}$ layers [17], have been identified as promising $p$-type thermoelectric materials. In this system, it has been shown that the substitution of Se by Te leads to an increase in electrical conductivity $[18,19]$, together with a reduction in the thermal conductivity $(\sim 0.97$ $\mathrm{W} \mathrm{m} \mathrm{K}^{-1}$ for BiOCuSe [20] and $0.68 \mathrm{~W} \mathrm{~m}^{-1} \mathrm{~K}^{-1}$ for BiOCuTe [21] at $373 \mathrm{~K}$ ). Consequently, the figure of merit of the oxytelluride ( $\mathrm{ZT}=0.42$ at $373 \mathrm{~K}$ ) is significantly higher than that of the oxyselenide ( $\mathrm{ZT}=0.15$ at $373 \mathrm{~K}$ ) [20,21]. In sharp contrast, the effect of substituting Se by $\mathrm{Te}$ in $\mathrm{Bi}_{2} \mathrm{O}_{2} \mathrm{Se}$ is not known, although the existence of a phase with stoichiometry $\mathrm{Bi}_{2} \mathrm{O}_{2} \mathrm{Te}$, together with its thermal stability, have been reported by Schmidt et al. $[9,22,23]$. To the best our knowledge, the thermoelectric properties of $\mathrm{Bi}_{2} \mathrm{O}_{2} \mathrm{Te}$ have never been investigated. Here, a detailed account of the structural, electrical and thermal transport properties of $\mathrm{Bi}_{2} \mathrm{O}_{2} \mathrm{Te}$ is presented. 


\section{Experimental}

\subsection{Sample preparation}

$\mathrm{Bi}_{2} \mathrm{O}_{2}$ Te was synthesised by solid state reaction in an evacuated and sealed silica tube $\left(<10^{-4}\right.$ Torr) from a mixture of $\mathrm{Bi}_{2} \mathrm{O}_{3}$ (99.99\%, Sigma Aldrich); $\mathrm{Bi}$ (99.5\%, Sigma Aldrich); and Te shot (99.9999\%, Alfa Aesar). The stoichiometric mixture was first heated up to $623 \mathrm{~K}$ for 15 hours and then up to $873 \mathrm{~K}$ for 5 hours with a $1 \mathrm{~K} \mathrm{~min}^{-1}$ ramp rate. A second annealing process at $873 \mathrm{~K}$ for a further 10 hours with a $2 \mathrm{~K} \mathrm{~min}^{-1}$ ramp rate was carried out after regrinding the obtained powders. For electrical and thermal transport measurements, the asprepared powder was hot-pressed into highly densified pellets $(\sim 95.7 \%$ of theoretical density) at $823 \mathrm{~K}$ and with a uniaxial pressure of 50 bars for 30 minutes under a $\mathrm{N}_{2}$ flow. For thermal conductivity measurements, a larger pellet, with $\sim 96.4 \%$ theoretical density, was pressed at 100 bars, and 2 square pieces cut from it. A square ingot was cut perpendicular to the direction of pressing, with dimensions $5.83 \times 5.83 \times 1.57 \mathrm{~mm}^{3}$, and a second square, with dimensions $5.85 \times 5.85 \times 1.46 \mathrm{~mm}^{3}$ was cut parallel to the direction of pressing.

\subsection{Characterization and physical property measurements}

\subsubsection{Structural and microstructural characterisation}

Samples were characterized by powder X-ray diffraction (XRD) using a Bruker D8 Advance Powder X-ray diffractometer, operating with germanium monochromated $\mathrm{CuK}_{\alpha 1}$ radiation $(\lambda$ $=1.54056 \AA$ ) and fitted with a LynxEye detector. Data were collected over a range of $5 \leq$ $2 \theta /^{\circ} \leq 120$, with a $0.022^{\circ}$ step, for a period of 7 hours. Rietveld refinements were carried out using the GSAS software [24]. A FEI Quanta FEG 600 scanning electron microscope was used to study the morphology of the sample, using a voltage of $20 \mathrm{kV}$ in high vacuum mode.

\subsubsection{Thermal analysis}

A TA-Q600SDT TGA instrument was used to investigate the thermal stability of $\mathrm{Bi}_{2} \mathrm{O}_{2} \mathrm{Te}$ as a function of temperature under a $\mathrm{N}_{2}$ flow. The sample was loaded into a ceramic crucible and heated from room temperature to $1000 \mathrm{~K}$, with a $5 \mathrm{~K} \mathrm{~min}^{-1}$ ramp rate.

\subsubsection{Electrical transport measurements}

To measure the electrical transport properties, a rectangular ingot $\left(\sim 6 \times 3 \times 1.2 \mathrm{~mm}^{3}\right)$ was cut from a hot pressed pellet. The electrical resistivity and Seebeck coefficient were measured simultaneously using a Linseis LSR-3 instrument (Germany) over the temperature range 300 $\leq \mathrm{T} / \mathrm{K} \leq 665$, under a temperature gradient of $30 \mathrm{~K}$ and an applied current of $15 \mathrm{~mA}$. 
Resistivity and Seebeck coefficient measurements were carried parallel to the pressing direction of the ingot. The charge carrier concentration (n) and mobility $(\mu)$ were calculated from the Hall coefficient and resistivity values measured using an Ecopia HMS-3000 Hall measurement system (Korea). A square sample with a length of $\sim 4 \mathrm{~mm}$ and thickness of $\sim 1$ $\mathrm{mm}$ was prepared. Indium solder was used for the electrical contacts. A magnetic field of -1 to 1 Tesla and the van der Pauw method [25] were applied to measure Hall coefficient and resistivity of sample, respectively.

\subsubsection{Thermal transport measurements}

A LFA 447 NanoFlash $^{\circledR}$ instrument was employed to measure the thermal diffusivity $(\alpha)$ and the heat capacity $\left(\mathrm{C}_{\mathrm{p}}\right)$ of the sample over a temperature range of $300 \leq \mathrm{T} / \mathrm{K} \leq 573$ in $50 \mathrm{~K}$ steps. The sample was a highly densified pellet with a diameter of approximate $12.7 \mathrm{~mm}$ and a thickness of $\sim 1.2 \mathrm{~mm}$. A graphite coating on the surface of the pellet was applied to maximize heat absorption. Thermal conductivity measurements were carried out perpendicular to the pressing direction of the ingot. In addition, measurements were also carried out on smaller square ingots, cut parallel and perpendicular to the direction of pressing. The thermal conductivity ( $\kappa$ ) is calculated from the relationship $\kappa=\alpha C_{p} \rho$, where $\rho$ is the sample density. A reference material, Pyroceram ${ }^{\mathrm{TM}} 9606$, was used as a reference for the determination of the heat capacity of sample.

\section{Results and discussion}

\subsection{Structural and morphological characterisation}

Powder X-ray diffraction data collected for $\mathrm{Bi}_{2} \mathrm{O}_{2}$ Te could be indexed on the basis of a bodycentered tetragonal unit cell, with slightly larger lattice parameters $(a \sim 3.9 \AA$ and $c \sim 12.7 \AA)$ than those previously reported for $\mathrm{Bi}_{2} \mathrm{O}_{2} \mathrm{Se}$ [5], suggesting than the structure of $\mathrm{Bi}_{2} \mathrm{O}_{2} \mathrm{Te}$ is closely related to that of $\mathrm{Bi}_{2} \mathrm{O}_{2} \mathrm{Se}$. In addition, our sample of $\mathrm{Bi}_{2} \mathrm{O}_{2}$ Te contains a trace amount of an impurity, which was identified as $\mathrm{Bi}_{2} \mathrm{TeO}_{5}$. A Rietveld refinement was carried out using the previously reported crystal structure of $\mathrm{Bi}_{2} \mathrm{O}_{2} \mathrm{Se}$ [5] as the initial structural model (space group $14 / \mathrm{mmm}$ ), with the Se atom at the $2(a)$ site replaced by Te. This resulted in good agreement between observed and calculated intensities, and a low $R_{w p}$ value. The final observed, calculated and difference profiles are shown in Fig. 1. The final refined parameters are presented in Table 1, while selected bond distances and angles are summarised in Table 2. Our refinement indicates that $\mathrm{Bi}_{2} \mathrm{O}_{2} \mathrm{Te}$ is isostructural with $\mathrm{Bi}_{2} \mathrm{O}_{2} \mathrm{Se}$, and crystallises in the anti- $\mathrm{ThCr}_{2} \mathrm{Si}_{2}$ structure type. The crystal structure of $\mathrm{Bi}_{2} \mathrm{O}_{2} \mathrm{Te}$ consists of $\left[\mathrm{Bi}_{2} \mathrm{O}_{2}\right]^{2+}$ layers and 
$\mathrm{Te}^{2-}$ square net layers alternately stacked along the $c$-axis (Fig. 2). The oxygen anions are tetrahedrally coordinated by four bismuth cations, at a distance of 2.3424(6) $\AA$, forming fluorite-type slabs. Each bismuth cation is at the centre of a square antiprism, surrounded by four oxygen and four tellurium anions, while the tellurium anions form a square array, with Te-Te distances of 3.98025(4) $\AA$. The Bi-O bond length of 2.3424(6) $\AA$ is shorter than the BiTe bond length of 3.4187(6) $\AA$. This is consistent with the larger ionic radius of $\mathrm{Te}^{2-}$ when compared with $\mathrm{O}^{2-}$, and with $\mathrm{Bi}-\mathrm{O}$ and $\mathrm{Bi}-\mathrm{Te}$ distances found in other bismuth oxytellurides [17]. The structure found for $\mathrm{Bi}_{2} \mathrm{O}_{2}$ Te is also adopted by $\mathrm{Th}_{2} \mathrm{~N}_{2} \mathrm{X}$ and $\mathrm{U}_{2} \mathrm{~N}_{2} \mathrm{X}(\mathrm{X}=\mathrm{Te}, \mathrm{Sb}, \mathrm{Bi})$ [26] as well as $\mathrm{RE}_{2} \mathrm{O}_{2} \mathrm{X}(\mathrm{RE}=$ rare-earth element, $\mathrm{X}=\mathrm{Te}, \mathrm{Sb}, \mathrm{Bi})[27,28,29,30]$. The fluoritetype $\left[\mathrm{Bi}_{2} \mathrm{O}_{2}\right]^{2+}$ layers are also found in the related $[\mathrm{BiO}][\mathrm{CuTe}]$ oxytelluride, where they alternate with anti-fluorite $\left[\mathrm{Cu}_{2} \mathrm{Te}_{2}\right]^{2-}$ layers [21]. The two-dimensional square nets of $\mathrm{Te}$ atoms found in $\mathrm{Bi}_{2} \mathrm{O}_{2} \mathrm{Te}$ are a characteristic structural motif in polytelluride compounds. In many cases it has been shown that structures containing Te-Te square nets are in fact average structures, with the real structures being strongly modulated [31]. The Te-Te distances in the $\mathrm{Bi}_{2} \mathrm{O}_{2} \mathrm{Te}$ square net are significantly larger $(\sim 3.98 \AA)$ than those in other polytelluride compounds containing square nets (typically 2.8 - 3.4 $\AA$ ), although still within the van der Waals contact distance of $4.2 \AA$. This suggests that the Te-Te interactions in $\mathrm{Bi}_{2} \mathrm{O}_{2} \mathrm{Te}$ will be rather weak. A commensurately modulated structure has been recently found for the related $\mathrm{Pr}_{2} \mathrm{O}_{2} \mathrm{Sb}$ [32], but our powder diffraction data for $\mathrm{Bi}_{2} \mathrm{O}_{2} \mathrm{Te}$ provides no evidence of a modulated structure.

Powder X-ray diffraction data collected on a hot-pressed sample indicates that the anti$\mathrm{ThCr}_{2} \mathrm{Si}_{2}$ structure of $\mathrm{Bi}_{2} \mathrm{O}_{2} \mathrm{Te}$ is retained during the consolidation process. No additional impurities are introduced, although the sample still contains a small amount of $\mathrm{Bi}_{2} \mathrm{TeO}_{5}$ (see Supplementary Information). Powder X-ray data show no evidence of preferred orientation in the hot-pressed sample. This is confirmed by measurements of the thermal conductivity on square ingots, cut perpendicular and parallel to the direction of pressing, which are included as Supplementary Information, and show that the thermal conductivity does not change depending on the direction of measurement. SEM images of the as-synthesised powder and a fracture surface of the hot-pressed sample (Fig. 3) indicate that the initial powder contains plate-like grains with a length of $c a .2 \mu \mathrm{m}$ and a thickness of $c a .0 .2 \mu \mathrm{m}$, whilst in the hotpressed sample the grain size is larger. TGA data collected on $\mathrm{Bi}_{2} \mathrm{O}_{2}$ Te under an inert atmosphere indicate that the onset of weight loss occurs around $900 \mathrm{~K}$ (Fig. 4), which is 
consistent with the decomposition temperature of $893 \mathrm{~K}$ previously reported by Schmidt et al. [22]

\subsection{Electrical and thermal transport properties}

The temperature dependence of electrical conductivity $(\sigma)$, Seebeck coefficient $(S)$ and power factor $\left(\mathrm{S}^{2} \sigma\right)$ of $\mathrm{Bi}_{2} \mathrm{O}_{2} \mathrm{Te}$ are shown in Figure 5. The electrical conductivity increases with increasing temperature, whilst the Seebeck coefficient is negative, indicating that this material behaves as an $n$-type semiconductor. As illustrated by the inset in Fig. 5, the temperature dependence of the electrical conductivity follows an Arrhenius law over the temperature range $300 \leq \mathrm{T} / \mathrm{K} \leq 585$. The activation energy determined from the $\ln \sigma \mathrm{vs} .1 / \mathrm{T}$ plot was used to estimate the band gap, taking into account that for an intrinsic semiconductor $\mathrm{E}_{\mathrm{g}}=2 \mathrm{E}_{\mathrm{a}}$ (Table 3). The Seebeck coefficient shows a clear change in its temperature dependence, and exhibits a broad maximum centred at $585 \mathrm{~K}$, which could be related to the onset of bipolar conduction. The band gap can also be estimated from the maximum value of the Seebeck coefficient $\left(\mathrm{S}_{\max }\right)$, using the expression $\mathrm{S}_{\max }=\mathrm{E}_{\mathrm{g}} /\left(2 e \mathrm{~T}_{\max }\right)$, where $e$ is the electron charge and $\mathrm{T}_{\max }$ is the temperature at which the maximum in the Seebeck coefficient occurs [33]. Taking into account that $S_{\max }$ occurs at $585 \mathrm{~K}$, a band gap of $0.23 \mathrm{eV}$ is found, in excellent agreement with the value determined using electrical conductivity data (Table 3). The band gap of $\mathrm{Bi}_{2} \mathrm{O}_{2} \mathrm{Te}$ is significantly lower than those reported for the isostructural $\mathrm{RE}_{2} \mathrm{O}_{2} \mathrm{Te}\left(\mathrm{E}_{\mathrm{g}} \sim 1.82 \mathrm{eV}\right)$ [34] and $\mathrm{Bi}_{2} \mathrm{O}_{2} \mathrm{Se}(0.78-1.28 \mathrm{eV})$ $[15,16]$, but comparable to that of BiOCuTe [17]. For $\mathrm{RE}_{2} \mathrm{O}_{2} \mathrm{Te}$, band structure calculations indicate that the top of the valence band is dominated by contributions from the Te $5 p$ and the O $2 p$ states, while the bottom of the conduction band is formed by rare-earth cation states [34]. Similarly, for $\mathrm{Bi}_{2} \mathrm{O}_{2} \mathrm{Se}$ the top of the valence band consist mainly of $\mathrm{Se} 4 p$ states, while the bottom of the conduction band consists primarily of $\mathrm{Bi} 6 p$ states [15]. In the case of BiOCuTe, it has been found that the contribution of $\mathrm{Bi} 6 p$ states to the bottom of the conduction band leads to a marked reduction in the band gap when compared with those of the rare-earth analogues [17]. A similar situation is likely to occur here. Optical measurements to determine band gap would be useful to confirm the results arising from the electrical transport property measurements, and in particular, to confirm that the band gap determined here is for intrinsic conduction, rather than for extrinsic charge carriers.

The power factor $\left(\mathrm{S}^{2} \sigma\right)$ of $\mathrm{Bi}_{2} \mathrm{O}_{2} \mathrm{Te}$ increases with temperature, approaching a value of 0.26 $\mathrm{mW} \mathrm{m} \mathrm{m}^{-1} \mathrm{~K}^{-2}$ at $655 \mathrm{~K}$. The values of the charge carrier concentration and mobility at room temperature are given in Table 3. The charge carrier concentration of $c a \cdot 10^{18} \mathrm{~cm}^{-3}$ is 
relatively low, and for thermoelectric applications doping would be required. A high charge carrier mobility is also desirable in thermoelectric materials, and the mobility of $\mathrm{Bi}_{2} \mathrm{O}_{2} \mathrm{Te}$ compares favourably with that of undoped BiOCuTe $\left(13 \mathrm{~cm}^{2} \mathrm{~V}^{-1} \mathrm{~s}^{-1}\right)$ [35], although it is lower than that of $\mathrm{Bi}_{2} \mathrm{Te}_{3}[36]$.

Figure 6 shows the temperature dependence of the thermal conductivity $(\kappa)$ and the figure of merit (ZT) of $\mathrm{Bi}_{2} \mathrm{O}_{2} \mathrm{Te}$ over the temperature range $300 \leq \mathrm{T} / \mathrm{K} \leq 573$. The total thermal conductivity $\left(\kappa_{\mathrm{tot}}\right)$ at room temperature is $\sim 0.91 \mathrm{~W} \mathrm{~m}^{-1} \mathrm{~K}^{-1}$, significantly lower than that of $\mathrm{Bi}_{2} \mathrm{Te}_{3}\left(\sim 2 \mathrm{~W} \mathrm{~m}^{-1} \mathrm{~K}^{-1}\right)$ [36]. The contribution of electronic $\left(\kappa_{\mathrm{e}}\right)$ and lattice $\left(\kappa_{\text {lat }}\right)$ thermal conductivity were estimated using the electrical conductivity data in conjunction with Wiedemann-Franz law, using a Lorenz constant of $2.45 \times 10^{-8} \mathrm{~W} \Omega \mathrm{K}^{-2}$. The lattice contribution is predominant, whilst the electronic contribution is only $0.6 \%$ of $\kappa_{\text {tot }}$ at room temperature and increases to $8.5 \%$ at $573 \mathrm{~K}$. When compared with $\mathrm{Bi}_{2} \mathrm{O}_{2} \mathrm{Se}$, which exhibits a thermal conductivity of $1.1 \mathrm{~W} \mathrm{~m}^{-1} \mathrm{~K}^{-1}$ at room temperature [12], the thermal conductivity follows the normal trend of decreasing with increasing mean atomic weight [4]. The low thermal conductivity of this material may be related to its two-dimensional nature, which may lead to scattering of phonons at the interfaces between the oxide and the chalcogen layers [37]. It has also been proposed that in compounds containing cations with lone pairs, such as $\mathrm{Sb}^{3+}$ or $\mathrm{Bi}^{3+}$, the anharmonicity of the bonds may lead to lattice thermal conductivities near the amorphous limit [38]. In other layered materials with very low thermal conductivities, such as $\mathrm{SnSe}$ and $[\mathrm{BiO}][\mathrm{CuSe}],[39,40]$ the Gruneisen parameter, which provides a measure of the strength of the lattice anharmonicity, is unusually large. This has been linked to "soft" bonding and the presence of lone pairs. Measurements of the elastic properties of $\mathrm{Bi}_{2} \mathrm{O}_{2} \mathrm{Te}$, and in particular determination of the Gruneisen parameter, may shed some light on the origin of its low thermal conductivity.

The thermoelectric figure of merit of $\mathrm{Bi}_{2} \mathrm{O}_{2} \mathrm{Te}$ increases as a function of temperature and reaches a value of 0.13 at $573 \mathrm{~K}$ (Fig. 5). Extrapolation of the thermal conductivity to $665 \mathrm{~K}$ leads to an estimated value of $\mathrm{ZT} \sim 0.2$ which is markedly higher than that of $\mathrm{Bi}_{2} \mathrm{O}_{2} \mathrm{Se}$ at the same temperature $(\mathrm{ZT} \sim 0.1)[12]$. Given that the values reported here have been obtained for an undoped material, there should be considerable scope for the improvement of ZT through doping to increase the charge carrier concentration.

\section{Conclusions}


We have established that $\mathrm{Bi}_{2} \mathrm{O}_{2}$ Te is an $n$-type semiconductor which crystallises in the anti$\mathrm{ThCr}_{2} \mathrm{Si}_{2}$ structure type. $\mathrm{Bi}_{2} \mathrm{O}_{2} \mathrm{Te}$ exhibits a band gap intermediate between those of $\mathrm{Bi}_{2} \mathrm{Te}_{3}$ $(0.13 \mathrm{eV})$ [36] and PbTe $(0.33 \mathrm{eV})$ [41], which would be appropriate for low-grade waste heat recovery applications. In common with other recently reported oxychalcogenides $[20,21]$, the thermal conductivity of $\mathrm{Bi}_{2} \mathrm{O}_{2} \mathrm{Te}$ is extremely low for a crystalline material. This leads to a thermoelectric figure of merit of 0.13 at $573 \mathrm{~K}$, despite the low charge carrier concentration found for this undoped material. Our current research efforts are centred on optimising the charge carrier concentration, in order to achieve thermoelectric performances comparable to those of the $p$-type oxychalcogenides.

\section{Acknowledgements}

We thank the Energy Technology Partnership and European Thermodynamics Ltd. for funding this project.

\section{Supplementary Information}

Powder diffraction data for the hot-pressed pellet and thermal diffusivity and heat capacity data have been included. Thermal conductivity on square ingots cut perpendicular and parallel to the direction of pressing have also been included.

\section{References}

[1] D. M. Rowe, Renew. Energ, 16 (1999) 1251-1256

[2] D. M. Rowe, Thermoelectrics Handbook: Macro to Nano ed. D M Rowe (Boca Raton FL: CRC Press), 2006, ch. 1

[3] A. P. Gonçalves, C. Godard, Eur. Phys. J. B 87 (2014) 42

[4] G. S. Nolas, J. Sharp, H. J. Goldsmid, Thermoelectrics: Basic Principles and New Materials Developments, Springer, Berlin, 2001.

[5] H. Boller, Monatsh. Chem. 104 (1973) 916-919

[6] H. Oppermann, H. Göbel, H. Shadow, V. Vassilev, I. Markova-Deneva, Z. Anorg. Allg. Chem. 622 (1996) 2115-2218

[7] H. Oppermann, H. Göbel, U. Petasch, J. Therm. Anal. 47 (1996) 595-604

[8] H. Oppermann, H. Göbel, Solid State Ionics 101-103 (1997) 1267-1272

[9] P. Schmidt, O. Rademacher, H. Opperman, Z. Anorg. Allg. Chem. 625 (1999) 255-261 
[10] H. Oppermann, H. Göbel, P. Schmidt, H. Shadow, V. Vassilev, I. Markova-Deneva, Z. Naturforsch. 54b (1999) 261-269

[11] P. Schmidt, H. Oppermann, Z. Naturforsch. 55b (2000) 627-637

[12] P. Ruleova, C. Drasar, P. Losak, C.-P. Li, S. Ballikaya, C. Uher, Mater. Chem. Phys. 119 (2010) 299-302

[13] C. Drasar, P. Ruleova, L. Benes, P. Lostak, J. Electron. Mater. 41 (2012) 2317-2321

[14] K. Zhang, C. Hu, Z. Kang, S. Wang, Y. Xi, H. Liu, Mater. Res. Bull. 48 (2013) 3968-3972

[15] T. V. Quang, H. Lim, M. Kim, J. Korean. Phys. Soc. 61 (2012) 1728-1731

[16] D. Guo, C. Hu, Y. Xi, and K. Zhang, J. Phys. Chem. C. 117 (2013) 21597-21602

[17] H. Hiramatsu, H. Yanagi, T. Kamiya, K. Ueda, M. Hirano, H. Hosono, Chem. Mater. 20 1 (2008) 326-334

[18] Y. Liu, J. Lan, W. Xu, Y. Liu, Y.-L. Pei, B. Cheng, D.-B. Liu, Y.-H. Lin, L.-D. Zhao, Chem. Commun. 49 (2013) 8075-8077

[19] D. Zou, S. Xie, Y. Liu, J. Lin and J. Li, J. Mater. Chem. A 1 (2013) 8888-8896

[20] S. D. N. Luu and P. Vaqueiro, J. Mater. Chem. A 1 (2013) 12270-12275

[21] P. Vaqueiro, G. Guelou, M. Stec, E. Guilmeau and A. V. Powell, J. Mater. Chem. A 1 (2013) 520-523

[22] P. Schmidt, O. Bosholm, H. Oppermann, Z. Naturfosch. 52b (1997) 1461-1466

[23] P. Schmidt, O. Rademacher, H. Oppermann, S. Dabritz, Z. Anorg. Allg. Chem. 626 (2000) 1999-2003

[24] A. C. Larson and R. B. von Dreele "General Structure Analysis System (GSAS)", Los Alamos National Laboratory Report LAUR (2004) 86-748

[25] L. J. Van der Pauw, Philips Tech. Rev. 268 (1958) 220-224

[26] R. Benz, W. H. Zachariasen, Acta Cryst. B26 (1970) 823-827

[27] R. Ballestraeci, Compt. Rend. Hebd. Seances Acad. Sci. B 264 (1967) 1736-1738

[28] R. Benz, Acta Cryst. B 27 (1971) 853-854

[29] F. A. Weber, T. Schleid, Z. Anorg. Allg. Chem. 625 (1999) 1833-1838

[30] H. Mizoguchi, H. Hosono, J. Am. Chem. Soc. 133 (2011) 2394-239.

[31] R. Patschke, M. G. Kanatzidis, Phys. Chem. Chem. Phys. 4 (2002) 3266-3281

[32] O. V. Magdysyuk, J. Nuss, M. Jansen, Acta Cryst. B69 (2013) 547-555

[33] H. J. Goldsmid, J. W. Sharp, J. Electron. Mater. 28 (1999) 869-872

[34] A. Mahmood, S.M. Ramay, Y. Saeed, Optoelectron. Adv. Mat. 8 (2014) 724-726 
[35] T.-H. An, Y. S. Lim, H.-S. Choi, W.-S. Seo, C.-H. Park, G.-R. Kim, C. Park, C. H. Lee, J. H. Shim, J. Mater. Chem. A 2 (2014) 19759-19764

[36] H. Scherrer and S. Scherrer, CRC Handbook of Thermoelectrics, ed. D. M. Rowe, CRC Press, Boca Raton, FL, 1995, ch. 19

[37] C. Wan, Y. Wang, N. Wang, W. Norimatsu, M. Kusunoki and K. Koumoto, Sci.

Technol. Adv. Mater. 11 (2010) 044306

[38] M. D. Nielsen, V. Ozolins, J. P. Heremans, Energy Environ. Sci. 6 (2013) 570-578.

[39] L.-D. Zhao, S.-H. Lo, Y. Zhang, H. Sun, G. Tan, C. Uher, C. Wolverton, V. P. Dravid, M. G. Kanatzidis, Nature 508 (2014) 373-377.

[40] Y.-L. Pei, J. He, J.-F. Li,. F. Li, Q. Liu, W. Pan, C. Barreteau, D. Berardan, N. Dragoe, L.-D. Zhao, NPG Asia Materials 5 (2013) e47.

[41] C. Wood, Rep. Prog. Phys. 51 (1988) 459-539 


\section{Figure captions}

\begin{tabular}{|c|c|}
\hline Figure 1 & $\begin{array}{l}\text { Rietveld refinement using powder X-ray diffraction data for } \mathrm{Bi}_{2} \mathrm{O}_{2} \mathrm{Te} \text {. Key: } \\
\text { observed data (red cross); difference curve (blue line); calculated pattern } \\
\text { (green line) and reflection positions of } \mathrm{Bi}_{2} \mathrm{O}_{2} \mathrm{Te} \text { (pink markers). The inset } \\
\text { shows the strongest reflection of the } \mathrm{Bi}_{2} \mathrm{OTe}_{5} \text { impurity, which has been } \\
\text { marked with an arrow. }\end{array}$ \\
\hline Figure 2 & $\begin{array}{l}\text { Ball-and-stick representation of the crystal structure of } \mathrm{Bi}_{2} \mathrm{O}_{2} \mathrm{Te} \text {. Key: } \mathrm{Bi} \text {, } \\
\text { blue circle; } \mathrm{O} \text {, red circle; Te, yellow circle. }\end{array}$ \\
\hline Figure 3 & $\begin{array}{l}\text { SEM micrographs of } \mathrm{Bi}_{2} \mathrm{O}_{2} \mathrm{Te} \text { for (a) and (b) as-synthesised powder; (c) } \\
\text { hot-pressed sample. }\end{array}$ \\
\hline Figure 4 & Thermogravimetric data for $\mathrm{Bi}_{2} \mathrm{O}_{2} \mathrm{Te}$ collected under a $\mathrm{N}_{2}$ atmosphere. \\
\hline Figure 5 & $\begin{array}{l}\text { Temperature dependence of the electrical conductivity }(\sigma) \text {, Seebeck } \\
\text { coefficient }(\mathrm{S}) \text {, and power factor }\left(\mathrm{S}^{2} \sigma\right) \text { of } \mathrm{Bi}_{2} \mathrm{O}_{2} \text { Te. The inset contains an } \ln \sigma \\
\text { vs } 1 / \text { T plot, where the solid line shows the best linear fit. }\end{array}$ \\
\hline Figure 6 & $\begin{array}{l}\text { Temperature dependence of thermal conductivity and figure of merit of } \\
\mathrm{Bi}_{2} \mathrm{O}_{2} \mathrm{Te} \text {. }\end{array}$ \\
\hline
\end{tabular}




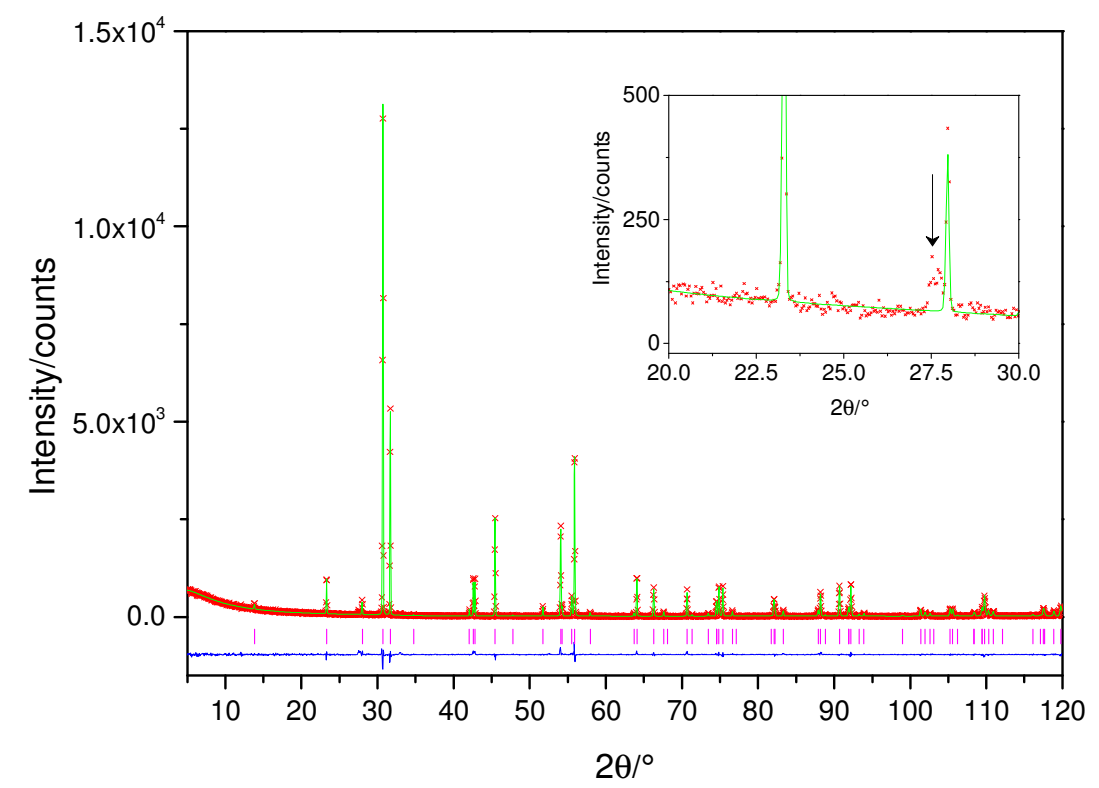

Figure 1 


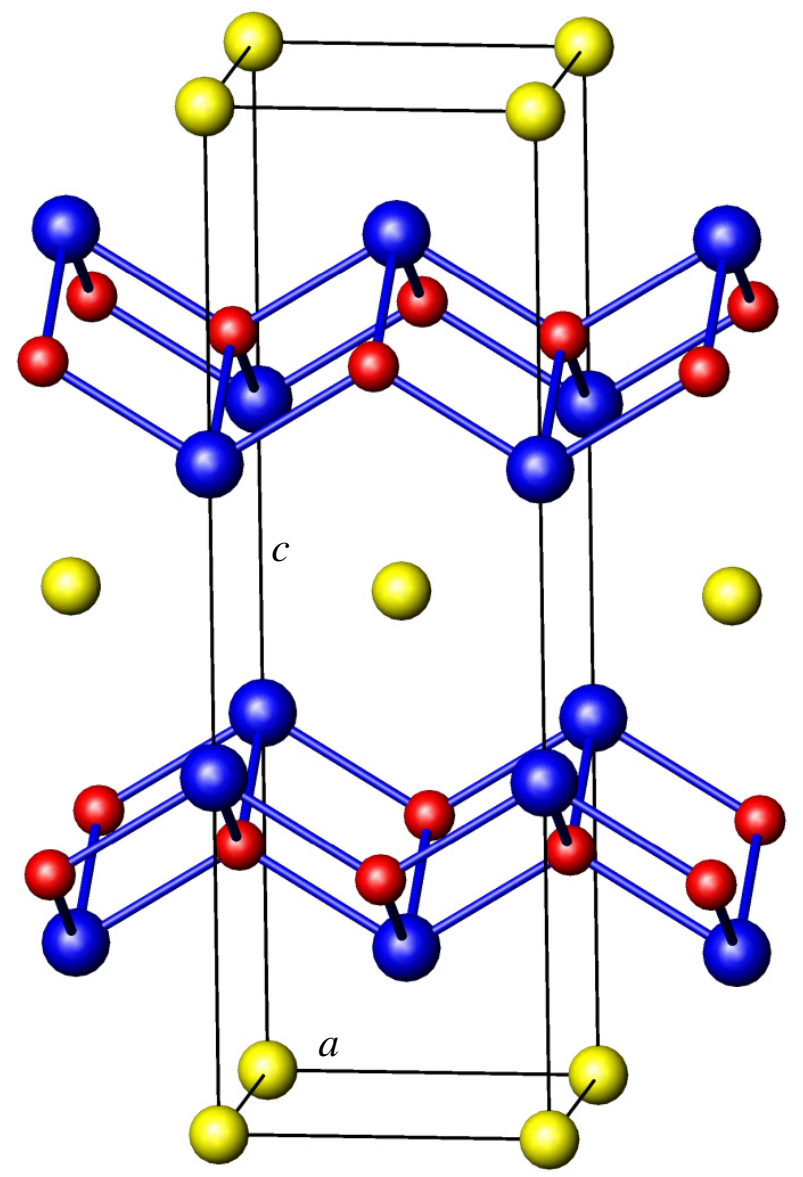

Figure 2 

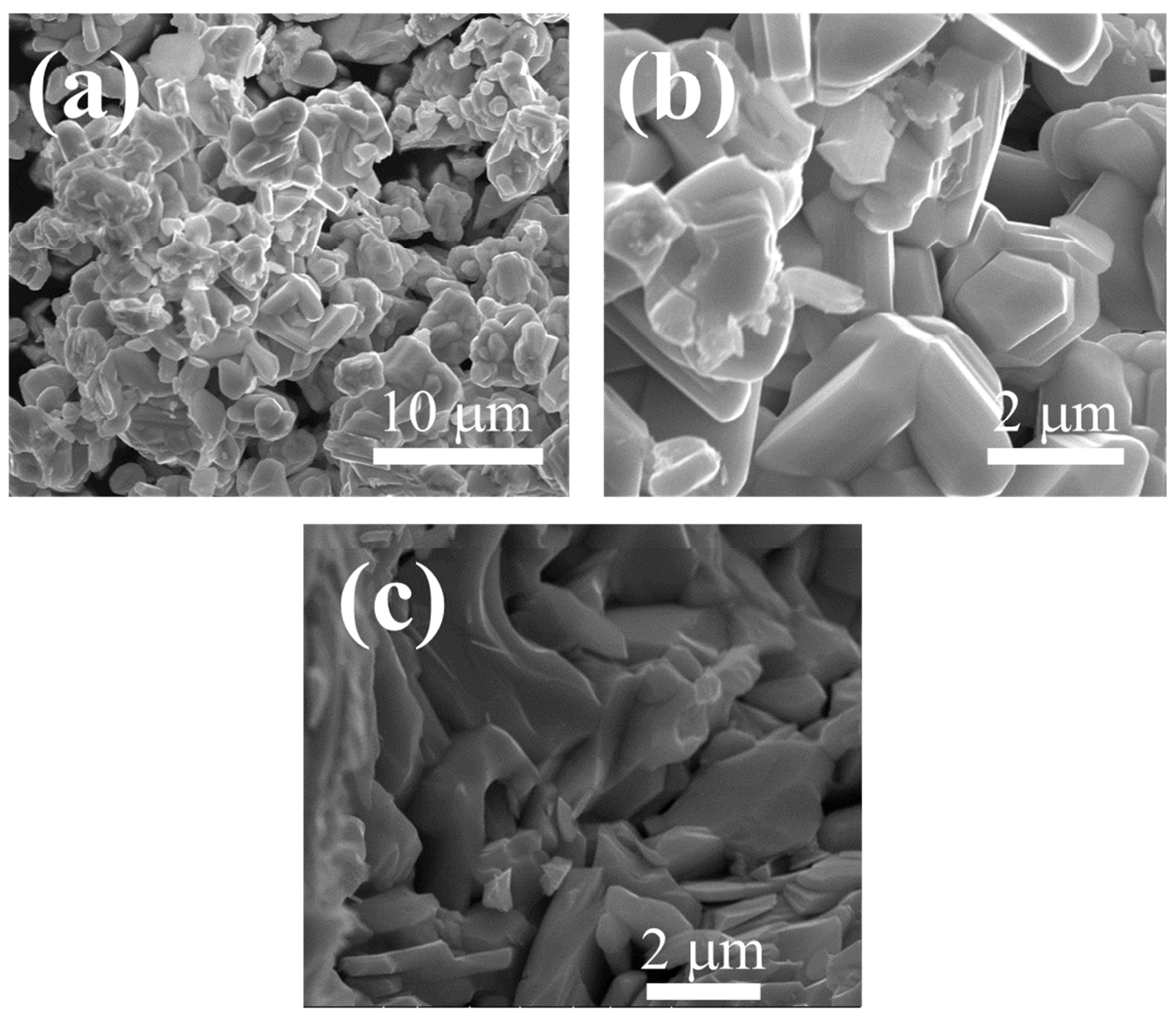

Figure 3 


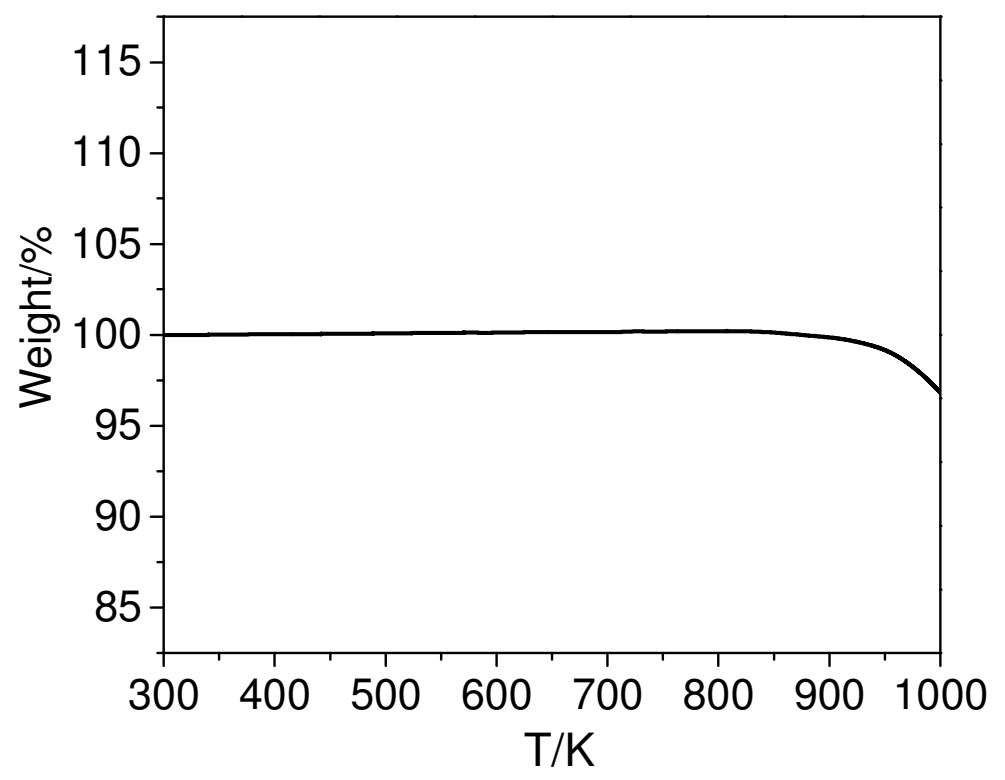

Figure 4 


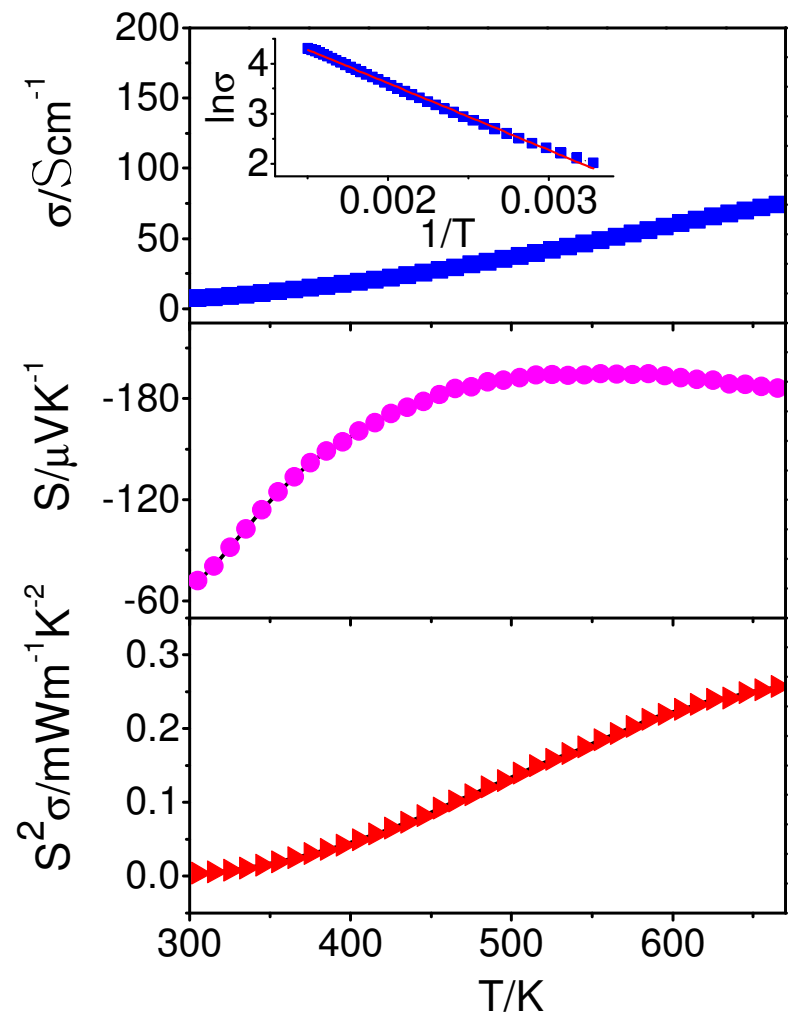

Figure 5 


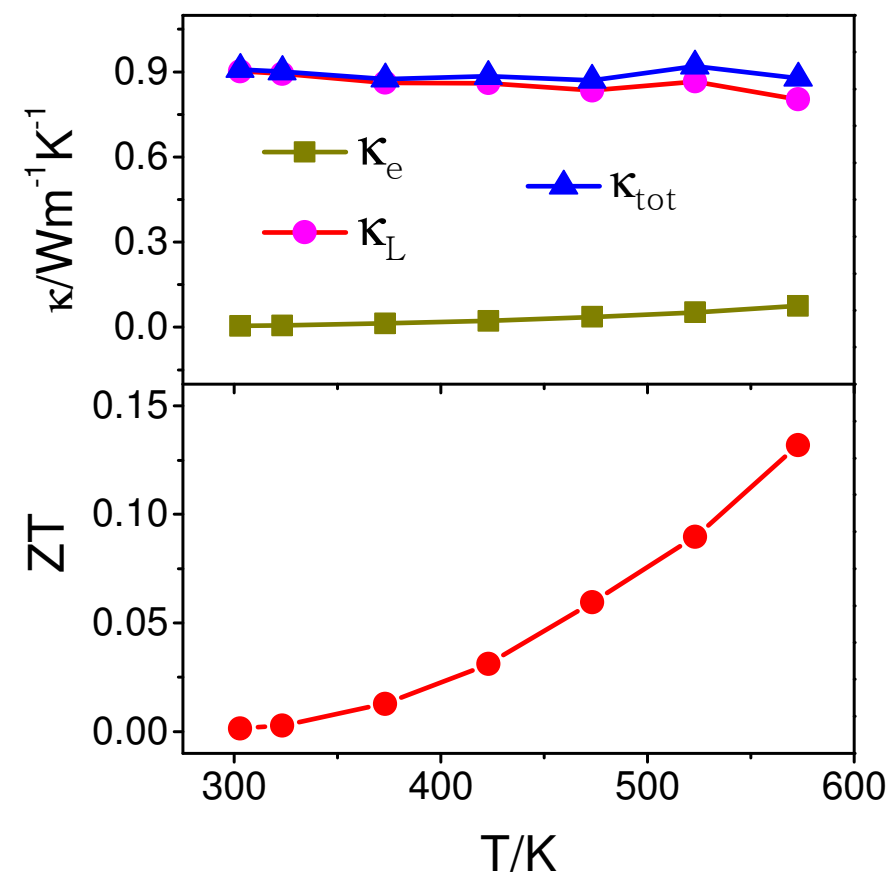

Figure 6 
Table. 1. Final refined parameters for $\mathrm{Bi}_{2} \mathrm{O}_{2} \mathrm{Te}$ at room temperature.

\section{$I 4 / \mathrm{mmm}$}

\begin{tabular}{ccccccc} 
& \multicolumn{6}{c}{$\boldsymbol{a}=3.98025(4) ; c=12.70391(16) \AA$} \\
\hline $\mathrm{Bi}$ & Site & $\mathbf{x}$ & $\mathbf{y}$ & $\mathbf{z}$ & $\mathbf{U}_{\text {iso }}\left(\AA^{2}\right)$ & Occupancy \\
\hline $\mathrm{Te}$ & $2(e)$ & 0 & 0 & $0.34724(9)$ & $0.00325(33)$ & 1.0 \\
$\mathrm{O}$ & 0 & 0 & 0 & $0.00256(63)$ & 1.0 \\
\hline & $4(d)$ & $1 / 2$ & 0 & $1 / 4$ & $0.0030(47)$ & 1.0 \\
\hline \hline
\end{tabular}

Table 2. Selected distances $(\AA)$ and angles $\left(^{\circ}\right)$.

\section{Bond length}

$\begin{array}{ll}d_{\text {Bi-O }} & 2.3424(6) \\ d_{\text {Bi-Bi }} & 3.7451(14) \\ d_{\text {Bi-Te }} & 3.4187(6) \\ \text { Bond angle } & \\ \text { O-Bi-O } & 116.34(5) \\ & 73.850(21) \\ \text { Bi-O-Bi } & 116.34(5) \\ & 106.150(21)\end{array}$

Table.3. Charge carrier concentration $(n)$, mobility $(\mu)$, electrical conductivity $(\sigma)$ at room temperature, together with the activation energy $\left(E_{a}\right)$ and band gap $\left(E_{g}\right)$ determined using data collected over the temperature range $300 \leq \mathrm{T} / \mathrm{K} \leq 665$.

\begin{tabular}{ccccc}
\hline $\mathbf{n}\left(\mathbf{c m}^{-3}\right)$ & $\mu\left(\mathbf{c m}^{2} \mathbf{V}^{-1} \mathbf{s}^{-1}\right)$ & $\boldsymbol{\sigma}\left(\mathbf{S . c m}^{-1}\right)$ & $\mathbf{E}_{\mathbf{a}}(\mathbf{e V})$ & $\mathbf{E}_{\mathbf{g}}(\mathbf{e V})$ \\
\hline $1.06 \times 10^{18}$ & 47 & 7.48 & 0.12 & 0.23 \\
\hline
\end{tabular}

